\title{
Análise dos efeitos da política Sistema Universidade Aberta do Brasil na perspectiva dos egressos da Universidade Estadual de Maringá
}

\section{Analysis of the effects of the policy Open University System of Brazil from the perspective of graduates of the State University of Maringá}

\author{
Análisis de los efectos de la política Sistema \\ Universidad Abierta de Brasil en la perspectiva de los \\ egresados de la Universidad Estatal de Maringá
}

Silvana Aparecida Guietti ${ }^{1}$

Maria Luisa Furlan Costa ${ }^{1}$

DOI: http://dx.doi.org/10.20435/serie-estudos.v24i51.1286

\begin{abstract}
Resumo: O Sistema Universidade Aberta do Brasil (UAB) foi instituído pelo Decreto n. 5.800, de 8 de junho de 2006, e tem como principal finalidade a formação de professores para atuar na educação básica. O presente artigo apresenta o resultado de um estudo que buscou analisar os efeitos da política desenvolvida pela UAB na perspectiva dos egressos do curso de Pedagogia, na modalidade de Educação a Distância (EaD), da Universidade Estadual de Maringá (UEM), turma $2009^{2}$. Trata-se de uma pesquisa qualitativa vinculada ao campo das políticas educacionais, que engloba estudos teóricos e empíricos. Os resultados indicam que os benefícios obtidos posteriormente à realização do curso de Pedagogia EaD/UEM, no âmbito do Sistema UAB, ultrapassam a expansão do número de vagas no ensino superior. Constatou-se que ocorreram melhorias na vida profissional e pessoal dos sujeitos pesquisados.
\end{abstract}

Palavras-chave: Universidade Aberta do Brasil; educação a distância; egressos.

Abstract: The Open University of Brazil (UAB) system was instituted by Decree n. 5,800, of June $8^{\text {th }}, 2006$, and its main purpose is to train teachers to work in basic education. The present article

\footnotetext{
${ }^{1}$ Universidade Estadual de Maringá (UEM), Maringá, Paraná, Brasil.

2 Este artigo decorre dos resultados obtidos da tese de doutorado desenvolvida no Programa de Pós-Graduação em Educação da Universidade Estadual de Maringá (UEM), Paraná, Brasil. Elegeu-se o curso de Pedagogia EaD/UEM, turma 2009, por se tratar da primeira turma de licenciatura ofertada pela UEM no âmbito do Sistema UAB.
} 
presents the results of a study that sought to analyze the effects of the policy developed by the $U A B$ in the perspective of graduates of the Pedagogy course in the mode of Distance Education (EaD) of the State University of Maringá (UEM), 2009 class. It is a qualitative research linked to the field of educational policies, which encompasses theoretical and empirical studies. The results indicate that the benefits obtained after completing the EaD/UEM Pedagogy course under the UAB System exceed the expansion of the number of places in higher education. It was found that there were improvements in the professional and personal life of the subjects surveyed.

Keywords: Open University of Brazil; distance education; graduates.

Resumen: El Sistema Universidad Abierta de Brasil (UAB) fue instituido por el Decreto no 5.800, de 8 de junio de 2006, y tiene como principal finalidad la formación de profesores para actuar en la educación básica. El presente artículo presenta el resultado de un estudio que buscó analizar los efectos de la política desarrollada por la UAB en la perspectiva de los egresados del curso de Pedagogía en la modalidad de Educación a Distancia (EaD) de la Universidad Estatal de Maringá (UEM), clase 2009. Se trata de una búsqueda cualitativa vinculada al campo de las políticas educativas, que engloba estudios teóricos y empíricos. Los resultados indican que los beneficios obtenidos posteriormente a la realización del curso de Pedagogía EaD/UEM, en el ámbito del Sistema UAB, sobrepasan la expansión del número de plazas en la enseñanza superior. Se constató que ocurrieron mejoras en la vida profesional y personal de los sujetos investigados.

Palabras clave: Universidad Abierta de Brasil; educación a distancia; egresados.

\section{INTRODUÇÃO}

A política de formação docente no Brasil passou por transformações a partir da década de 1990. Isso se deve especialmente ao consenso criado por meio da Conferência Mundial de Educação para Todos, realizada em Jomtien, na Tailândia, em 1990, e da Conferência de Nova Delhi, em 1993, na Índia, em torno do papel da Educação no desenvolvimento social e econômico de diversos países, considerados em desenvolvimento por organizações internacionais como o Banco Mundial (BM) e a Organização de Cooperação de Desenvolvimento Econômico (OCDE).

No Brasil foram redigidos documentos educacionais balizados pelas Conferências citadas: o Plano Decenal de Educação para Todos (BRASIL, 1993); Lei de Diretrizes e Bases da Educação Nacional (LDBEN)- Lei n. 9.394/96 (BRASIL, 1996). Esses Documentos expressavam a intenção de ampliar o atendimento educacional brasileiro na Educação Básica, e por conseguinte, na formação docente.

Verifica-se que a LDBEN- Lei n. 9.394/96 (BRASIL, 1996) possibilitou a utilização da modalidade a distância para a ampliação dos processos formativos, o que tornou possível a criação de políticas para a formação de professores nessa modalidade de ensino. Assim, no ano de 2006, tem-se a instituição do Sistema 
Universidade Aberta do Brasil (UAB), por meio do Decreto n. 5.800/06 (BRASIL, 2006b).

Este artigo tem como objetivo analisar os efeitos da política desenvolvida pela UAB na perspectiva dos egressos do curso de Pedagogia na modalidade de Educação a Distância (EaD) da Universidade Estadual de Maringá (UEM), turma 2009, mediante a abordagem do "ciclo de políticas" proposto por Bowe et al. (1992), Ball (1994), referenciado e utilizado por Mainardes (2006), Mainardes e Marcondes (2009).

Para tanto, inicialmente discutimos a abordagem do "ciclo de políticas" como método de pesquisa em política educacional. Na sequência, enfocamos a Universidade Aberta do Brasil em seus diferentes contextos: "contexto da influência; da "produção do texto"; "contexto da prática"; e por fim, analisamos os efeitos da política proposta pelo Sistema UAB, na perspectiva dos egressos do curso de Pedagogia EaD/UEM, turma 2009.

\section{A ABORDAGEM DO CICLO DE POLÍTICAS}

Parte-se do pressuposto de que a análise e a compreensão de uma dada política educacional se caracterizam como uma tarefa complexa, portanto requer esforço teórico-metodológico por parte do pesquisador. Para Mainardes (2018, p. 192) "[...] a política educacional constitui-se em um campo de conhecimento específico, formado por conhecimento especializado".

Assim, necessita de método de análise que contemple suas especificidades. Nesse sentido, compreende-se que o "ciclo de políticas", proposto por Bowe et al. (1992), Ball (1994), referenciado e utilizado por Mainardes (2006), Mainardes e Marcondes (2009), como método contribui para análise de diferentes políticas, "[...] uma vez que o processo político é entendido como multifacetado e dialético, necessitando articular as perspectivas macro e micro" (MAINARDES, 2006, p. 55).

Dentre os aspectos que diferenciam a abordagem do "ciclo de políticas" dos demais métodos de análise de políticas, merece destaque a compreensão de que não há uma linearidade que simplifique a ação da política em: identificação do problema, formação da agenda, formulação da política, implementação, avaliação e extinção da política. Uma política educacional não é linear, tampouco previsível.

A abordagem do "ciclo de políticas" se diferencia de outros métodos de análise de políticas ao recomendar a compreensão de uma dada política por 
meio da observação de seus diferentes contextos. Na formulação inicial do "ciclo de políticas" ${ }^{\prime}$, Ball e seus colaboradores apresentaram três contextos políticos assim denominados: a política proposta, a política de fato e a política em uso. A política proposta refere-se à política oficial expressa pelo governo, assessores e instituições. A política de fato, expressa por textos escritos e legislações e, por fim a política em uso, no âmbito da prática (MAINARDES, 2006).

Posteriormente, Ball e seus colaboradores romperam com a formulação inicial do "ciclo de políticas" e introduziram o termo "contínuo" no "ciclo de políticas", o qual passou a ser nominado de "ciclo contínuo de políticas", em referência a um movimento dinâmico e flexível, em contraposição a análises lineares das políticas.

Nesse período, essa abordagem compunha-se de três contextos: o da influência, o da produção do texto e o da prática (MAINARDES, 2006). O primeiro deles, o "contexto da influência", se inscreve no momento em que as políticas são iniciadas, mediante a construção dos discursos políticos. Participam dessa etapa partidos políticos, governo, legislativo e grupos representantes da sociedade organizada. "É neste contexto que grupos de interesse disputam para influenciar a definição das finalidades sociais da educação e do que significa ser educado" (MAINARDES, 2006, p. 51).

Há um campo de disputa na formulação do discurso que exerce influência na arena pública. Por vezes, o discurso recebe apoio de determinados grupos e, outras vezes, os interesses não se coadunam com o que está sendo proposto. Esse contexto é marcado por diversas influências internas e externas. Na esfera nacional e internacional, há disseminação de ideias provenientes de grupos que integram a esfera pública e privada.

No "contexto da produção do texto", são produzidos os textos políticos. Esses podem se apresentar nas mais variadas formas: textos legais oficiais e textos políticos; comentários formais ou informais sobre textos oficiais; pronunciamentos oficiais; vídeos, dentre outros. Com base em Ball e seus colaboradores, é que Mainardes (2006) apresenta duas questões a serem observadas sobre tal contexto: 1- os textos políticos não são claros ou coerentes; e, 2- a política não é finalizada no legislativo. Portanto destaca-se que "[...] os textos precisam ser

\footnotetext{
${ }^{3} \mathrm{O}$ "ciclo de políticas" constitui-se um conceito teórico formulado pelo sociólogo inglês, Stephen Ball, e colaboradores para designar o movimento de produção das políticas.
} 
lidos com relação ao tempo e ao local específico de sua produção" (MAINARDES, 2006, p. 52).

É no "contexto da prática" que a política acontece efetivamente. Os sujeitos envolvidos com a política interpretam, reinterpretam e a recriam. Nesse sentido, observa-se que o "[...] contexto da prática é onde a política está sujeita à interpretação e recriação e onde a política produz efeitos e consequências que podem representar mudanças e transformações significativas na política original (MAINARDES, 2006, p. 53).

Da citação anterior depreende-se que os formuladores das políticas não conseguem controlar os sentidos atribuídos aos textos políticos. Professores e demais atores sociais exercem um papel ativo no processo de ressignificação das políticas. O texto ou parte dele pode ser aceito ou ignorado. Assim como nos demais contextos, no "contexto da prática" diferentes interpretações estão em disputa. Determinadas vozes serão ouvidas e outras silenciadas.

Em 1994, Ball incorporou ao "ciclo contínuo de políticas" outros dois contextos: "contexto dos resultados ou efeitos e "contexto da estratégia política". Observa-se que a adição desses novos contextos à abordagem do "ciclo contínuo de políticas" sinalizam a preocupação de Ball e colaboradores com impacto das políticas públicas na sociedade. Em contraposição a perspectivas que consideram que as políticas apresentam apenas resultados, Ball e colaboradores salientam que as políticas causam impactos (MAINARDES, 2006).

Para Mainardes (2006), a utilização do termo "efeito" em contraposição a "resultado" para designar os retornos de uma política para o grupo social atendido é mais apropriado em razão da compreensão de que a política não está pronta. Essa sofre alterações no decorrer de seu percurso. Nesse sentido, é importante que as políticas sejam analisadas com vistas à compreensão do seu impacto e suas interações com as desigualdades existentes e formas de injustiças. Evidencia-se que análise dos efeitos da política tem como ponto central às questões de justiça, igualdade e liberdade individual.

O último contexto do "ciclo contínuo de políticas", denominado "contexto da estratégia política", encontra-se ligado à identificação de um conjunto de atividades sociais e políticas necessárias para trabalhar com as desigualdades criadas ou reproduzidas pela política investigada. Assim completa-se o "ciclo contínuo de políticas". 


\section{Em suma:}

[...] a abordagem do "ciclo de políticas" constitui-se num referencial analítico útil para a análise de programas e políticas educacionais e que essa abordagem permite a análise crítica da trajetória de programas e políticas educacionais desde sua formulação inicial até sua implementação no contexto da prática e seus efeitos. (MAINARDES, 2006, p. 48).

Mainardes e Marcondes (2009), amparados em Ball, identificam a necessidade do pesquisador abordar os contextos, apresentados pela abordagem "ciclo de políticas": "contexto da influência", "contexto de produção do texto", "contexto da prática", "contexto dos resultados ou efeitos" "contexto da estratégia política", uns dentro dos outros, a fim de que se possa fugir das armadilhas de métodos de estudos em política educacional, que abordem a política de forma linear e simplificada.

No estudo desenvolvido, elegeu-se a abordagem "ciclo de políticas" para analisar a política desenvolvida pelo Sistema UAB, em razão de esse método de pesquisa em política educacional proporcionar ferramentas que possibilitem a compreensão do referido objeto de estudo em toda a sua trajetória: do contexto da influência, passando pelos contextos da formulação, contexto da prática, dos efeitos da política, articulando as perspectivas macro e micro social, conforme orientam Mainardes (2006) e Mainardes e Marcondes (2009). Destaca-se que, na pesquisa realizada com os egressos do curso de Pedagogia, não foi tratado do último contexto, "contexto da estratégia política", devido não ser possível avaliar em uma política em andamento [Sistema UAB] as desigualdades produzidas por esta.

\section{A UAB EM SEUS DIFERENTES CONTEXTOS}

A proposta de criação de uma Universidade Aberta no Brasil, enquanto política educacional direcionada à expansão do número de vagas no ensino superior e, especialmente, para a formação docente, encontra-se marcada por um longo processo de discussão e de tramitação de diversos Projetos de Lei (PL) na Câmara Federal, até que, no ano de 2006, o Sistema Universidade Aberta do Brasil foi regulamentado. Nesse sentido, a elucidação de tal processo requer do pesquisador um método de análise que possibilite a historização da política, a fim de se compreender sua trajetória.

A produção de políticas é marcada por negociações e ações não planejadas de dentro e fora do Estado. A política está sujeita às diversas influências, no âmbito 
nacional e internacional na formulação legislativa, em função da articulação de grupos de interesses distintos que representam diferentes classes sociais. Devido a essas especificidades, o analista político necessita de um aporte teórico que lhe possibilite conhecer como as políticas são pensadas, formuladas, desenvolvidas e reinterpretadas no "contexto da prática".

Com relação ao Sistema UAB, retoma-se brevemente o "contexto da influência", da "produção do texto", "contexto da prática", para na sequência, analisarmos os efeitos da política desenvolvida pela UAB na perspectiva dos egressos do curso de Pedagogia, na modalidade a distância (EaD), da Universidade Estadual de Maringá (UEM), turma 2009.

\subsection{0 contexto da influência}

As primeiras discussões sobre a criação de uma Universidade Aberta no Brasil datam do início da década de 1970. Em 1972, uma delegação brasileira representada pelo então Ministro da Educação, Jarbas Passarinho, participou da 3a Conferência Internacional sobre Educação de Adultos, ocorrida em Tóquio, no Japão. Essa conferência foi realizada pela Organização das Nações Unidas para a Educação, a Ciência e Cultura (Unesco). Esses representantes do Brasil entraram em contato com a delegação inglesa e, por conseguinte, com a experiência da Universidade Aberta inglesa, a Open University ${ }^{4}$. Nesse mesmo ano, Newton Sucupira, enquanto Diretor da Comissão de Assuntos Internacionais do Ministério da Educação (MEC) visitou as universidades que integravam a Universidade Aberta da Inglaterra (LACÉ, 2014).

Como resultado da viagem de estudos à Universidade Aberta inglesa, Sucupira elaborou um Relatório, composto de observações e possíveis aplicações das ideias lá desenvolvidas em contexto brasileiro. Tem-se naquele momento, os primeiros estudos que sustentaram as discussões em torno da efetivação de uma Universidade Aberta em nosso país.

Para Lacé (2014), a partir da publicação do referido Relatório, no ano de 1973, foram desencadeadas ações com vistas à construção de um projeto de Universidade Aberta para o Brasil. Nesse período, dois Grupos de Trabalho (GT)

\footnotetext{
${ }^{4}$ Open University: criada em 1969, na Inglaterra com foco na formação de professores em nível superior (PETERS, 2003).
} 
foram criados com tal objetivo. Esses Grupos foram compostos por agentes do governo, burocratas do Estado, ligados ao Ensino Supletivo, como se pode observar na citação a seguir:

[...] no seu nascedouro, a ideia de Universidade Aberta estava vinculada à doutrina esposada para o ensino supletivo. A Universidade Aberta seria uma espécie de supletivo universitário embasada nos supostos delineados pelo Art. 14 da Lei de Diretrizes e Bases, n. 5.692/1971. (LACÉ, 2014, p. 251).

Sobre a intenção de criação da primeira Universidade Aberta brasileira, Lacé (2014) relata duas questões importantes. A primeira delas se refere à intenção, desde as primeiras discussões, no ano de 1972, de que a Universidade Aberta estaria vinculada ao MEC e ao setor público. A segunda questão diz respeito à finalidade da referida instituição. Na discussão inicial, pretendia-se que a Universidade Aberta ofertasse cursos superiores nas diferentes áreas do conhecimento. No entanto, posteriormente, o foco foi redirecionado para a formação de professores leigos.

Com base em Lacé (2014) pondera-se que a construção do discurso em torno da constituição da Universidade Aberta do Brasil se constituiu em um processo longo e complexo. Esse debate permeou a década de 1970, adentrando as décadas de 1980, 1990 e anos 2000. Participaram dessa ação inúmeros atores sociais de diferentes posicionamentos político-partidários.

Ao tratar do "contexto da influência", assim como foi apresentado no "ciclo de política", proposto por Bowe et al. (1992), Ball (1994), referenciado e utilizado por Mainardes (2006), Mainardes e Marcondes (2009), verifica-se que UAB recebeu interferência externa de organizações internacionais como a Unesco, da Open University, além das influências nacionais advindas de grupos políticos distintos, governo e do legislativo.

\subsection{0 contexto da produção do texto}

O "contexto da produção do texto" de uma dada política encontra-se estreitamente ligado ao "contexto da influência". Os textos produzidos resultam dos embates políticos, de diversas ideologias. Para Ball (2011), o contexto de produção de um texto é aberto. Esses textos traduzem os interesses e os compromissos de variadas influências e agendas, numa lógica de constante negociação e embate entre os envolvidos com a política proposta. 
Mainardes (2006) apresenta a seguinte explicação para o "contexto da produção do texto":

[...] os textos políticos normalmente estão articulados com a linguagem do interesse público mais geral. Os textos políticos, portanto, representam a política. Essas representações podem tomar várias formas: textos legais oficiais e textos políticos, comentários formais ou informais sobre os textos oficiais, pronunciamentos oficiais, vídeos etc. Tais textos não são, necessariamente, internamente coerentes e claros, e podem também ser contraditórios. Eles podem usar os termos-chave de modo diverso. A política não é feita e finalizada no momento legislativo e os textos precisam ser lidos com relação ao tempo e ao local específico de sua produção. (MAINARDES, 2006, p. 52).

Com relação à UAB, destaca-se a longevidade e a complexidade do "contexto da produção do texto". Nessa direção, Lacé (2014) evidencia iniciativas que datam de 1974, ano que foi apresentado o primeiro Projeto de Lei até o ano de criação do Sistema Universidade Aberta do Brasil, por meio do Decreto n. 5.800, de 08 de junho de 2006 (BRASIL, 2006b).

Lacé (2014) enfatiza que, entre os anos de 1972 a 1974, a temática da criação da Universidade Aberta do Brasil esteve presente na agenda governamental. No entanto, após o ano de 1974, essa discussão foi diluída em razão de o governo federal realizar a opção de continuar ofertando formação de professores em nível médio, por meio do Projeto Logos ${ }^{5}$, bem como pela conjuntura que o país apresentava no contexto da ditadura militar. Diante desse cenário o projeto Universidade Aberta do Brasil não avançou.

Constata-se que a década de 1980 transcorreu sem avanços em relação à construção da Universidade Aberta brasileira. Todavia Lacé (2014) menciona como iniciativa importante a produção do Documento Intitulado "Por uma Política Nacional de Aberta e a Distância" de 1989. Esse Documento salientava a necessidade da adoção da modalidade educação a distância, bem como o desenvolvimento de política educacional aberta e a distância, com ênfase na formação de professores e apresentava estratégias para a efetivação de políticas de EaD.

Com a promulgação da LDBEN- Lei n. 9.394/96 (BRASIL, 1996) e da edição dos Decretos n. 2.494/1998 (BRASIL, 1998) e do Decreto n. 5.622/2005 (BRASIL,

\footnotetext{
${ }^{5}$ Projeto Logos: destinado ao treinamento de professores leigos. No Brasil, foi desenvolvido o Projeto Logos I (a partir de 1972) e o Logos II (a partir de 1976) (GOUVEIA, 2016).
} 
2005a), a modalidade a distância passa a ser desenvolvida, em especial, para formar professores para atuarem na educação básica. Dentre as principais iniciativas, destaca-se, em 1996, a criação da Secretaria de Educação a Distância (SEED) que objetivava a expansão do número de vagas no ensino superior por meio da EaD (COSTA, 2010).

No ano de 2004, ações federais possibilitaram a formulação de políticas em EaD. Foram criados no âmbito da SEED três Departamentos: Departamento de Políticas em EaD, Departamento de Produção e Capacitação em Programas de EaD e o Departamento de Infraestrutura Tecnológica. Nesse mesmo ano, o governo lança o Edital de Chamada Pública, n. 001/2004-SEED-MEC, o Programa Inicial de Formação de Professores, Pró-Licenciatura 1, da rede pública e no ano seguinte, lança o Edital do Pró-Licenciatura 2. Consta, ainda, que, no dia 21 de setembro de 2004, foi criado o Fórum das Estatais pela Educação (FEE) que resultaria na instituição do Sistema UAB (COSTA, 2010).

No ano de 2005, o documento intitulado “Projeto: Universidade Aberta do Brasil" (BRASIL, 2005c), produzido pelo FEE, em suas considerações gerais, sinaliza que a "[...] rede de universidades brasileiras apresenta férteis potencialidades rumo à democratização do acesso, comprovada pela existência de um parque universitário robusto e malha consolidada de pesquisa" (BRASIL, 2005c, p. 1) e propõe a utilização das instituições de ensino superior, federais e estaduais, para a ampliação do número de vagas no ensino superior, em especial, para formação e capacitação de docentes da educação básica.

Diante dessa proposição, no ano de 2005, o Sistema Universidade Aberta do Brasil foi lançado pelo MEC no âmbito do FEE e, no ano seguinte, ocorreu a institucionalização formal desse Sistema, cujo o objetivo consiste em "I- oferecer, prioritariamente, cursos de licenciatura e de formação inicial e continuada de professores da educação básica" (BRASIL, 2006b). O Sistema UAB efetivou parcerias com entidades estatais como a Petrobrás, Banco do Brasil, dentre outros.

Reitera-se aqui a longa trajetória para que o Brasil pudesse ter sua primeira Universidade Aberta, datada do início da década de 1970 até o ano de 2006, com a efetivação do Sistema Universidade Aberta do Brasil. Verifica-se que, diferentemente do que foi pensado a partir da década de 1970 em relação à criação de uma Universidade Aberta com metodologia de EaD, no Brasil se efetivou o Sistema UAB, o qual não dispôs da criação de uma nova instituição de ensino. Esse Sistema 
funciona como órgão articulador das instituições públicas, responsáveis pela oferta de cursos superiores na modalidade a distância.

\subsection{0 contexto da prática}

Ao tratar do "contexto da prática" retomam-se três observações realizadas por Ball (2011): 1- as políticas são sempre endereçadas ao âmbito da prática; 2- é no "contexto da prática" que a política acontece de fato; 3- no "contexto da prática" a política é traduzida, interpretada e ressignificada. Com base nas observações anteriores, pode-se dizer que a tradução da política propalada pelo Sistema UAB se deu mediante à publicação dos Editais n. 1/2005-SEED/MEC (BRASIL, 2005b) e n. 1/2006-SEED/MEC (BRASIL, 2006c). O primeiro Edital se destinava a instituições de ensino superior públicas federais que apresentassem interesse em ofertar cursos na modalidade a distância. O segundo Edital contemplava instituições de ensino superior públicas estaduais e federais na oferta de cursos na modalidade a distância.

Dessa forma, as instituições públicas de ensino superior, que aderiram ao Sistema UAB, por meio dos Editais n. 1/2005-SEED/MEC (BRASIL, 2005b) e n. 1/2006- SEED/MEC (BRASIL, 2006c), passaram a ofertar cursos na modalidade EaD em articulação com os polos de apoio presencial. A formalização da colaboração entre os entes federados ocorreu por meio de acordos de cooperação técnica ou convênio com os entes interessados em manter polos de apoio presencial no Sistema UAB.

Costa (2010) sublinha que o Sistema UAB enquanto articulador entre instituições públicas de ensino superior, governos municipais e estaduais possui estrutura complexa. Identifica como pilares de sustentação da UAB as instituições públicas de Ensino Superior e os polos de apoio presencial. Explicita que cabe às instituições de ensino a formulação dos projetos para a oferta dos cursos, a produção do material didático e a oferta dos docentes. Com relação ao polo de apoio presencial, esse fica sob responsabilidade do município conveniado ao referido Sistema.

Em se tratando da política desenvolvida pelo Sistema UAB, no "contexto da prática" na Universidade Estadual de Maringá (UEM), pode-se dizer que essa se deu a partir do Edital n. 1/2006- SEED/MEC (BRASIL, 2006c). A UEM, como integrante do Sistema $\cup A B$, segue suas prerrogativas em relação ao desenvolvimento de cursos na modalidade a distância. Assim, se responsabiliza pela elaboração e 
aprovação dos projetos pedagógicos dos cursos ofertados, bem como pela elaboração dos materiais didáticos e a disponibilização dos docentes.

Mediante a realização do Vestibular Unificado, realizado pela UEM, no segundo semestre de 2008, no ano seguinte teve início o curso de Pedagogia, na modalidade a distância, primeiro curso de licenciatura da UEM, desenvolvido no âmbito do Sistema UAB. Os acadêmicos pertenciam aos polos de apoio presencial localizados nos seguintes municípios paranaenses: Assaí, Astorga, Bela Vista do Paraíso, Cidade Gaúcha, Engenheiro Beltrão, Faxinal, Flor da Serra do Sul, Goioerê, Itambé, Jacarezinho, Nova Londrina, Nova Santa Rosa, Sarandi e Umuarama (UEM, 2008).

O término desse curso se deu no ano de 2012. De acordo com os dados disponibilizados às pesquisadoras pela Diretoria de Assuntos Acadêmicos (DAA) UEM), 376 (trezentos e setenta e seis) alunos concluíram o curso. Desse número de egressos, 126 (cento e vinte e seis) fizeram parte da pesquisa de campo desenvolvida sobre os efeitos da política desenvolvida pelo Sistema UAB na perspectiva de seus egressos, cujos dados serão analisados no próximo tópico deste artigo.

Com relação à política proposta pelo Sistema UAB no "contexto da prática", em especial na UEM, concorda-se com Ball, Maguire e Braun (2016, p. 21) ao afirmarem que "[...] colocar as políticas em prática é um processo criativo, sofisticado e complexo". Neste estudo, observou-se que essa instituição passou por um processo de estruturação para a oferta do Curso de Pedagogia/EaD, turma 2009. Realizaram-se mudanças no formato de atendimento aos discentes, em termos logístico, administrativo e pedagógico.

\section{O SISTEMA UAB NA PERSPECTIVA DOS EGRESSOS DO CURSO DE PEDAGOGIA EAD/UEM, TURMA 2009}

O atendimento ao objetivo da pesquisa realizada que buscou analisar os efeitos da política desenvolvida pela UAB na perspectiva dos egressos do curso de Pedagogia na modalidade a distância (EaD) da Universidade Estadual de Maringá (UEM), turma 2009, contou com estudos teórico e empírico. No estudo de campo, utilizou-se o instrumento questionário, bem como a "análise de conteúdo" (BARDIN, 2016).

Com base na abordagem adotada no trabalho que deu origem a este artigo, o "ciclo de políticas", proposto por Bowe, Ball e Gold (1992), Ball (1994), 
referenciado e utilizado por Mainardes (2006), Mainardes e Marcondes (2009), enfatiza-se que o conhecimento dos efeitos de uma política para a população a que se destinou, constitui-se numa atividade relevante. A atribuição de voz ao egresso pode revelar aspectos desconhecidos ou impensados por parte dos formuladores da política. Entende-se que:

[...] egressos de programas e políticas sociais são sujeitos especialmente interessantes para compreendermos como esses programas e políticas se articulam com a sociedade. Eles são uma fonte privilegiada de informações que permitem entender o alcance, efeitos e conseqüências de uma ação educativa. (DAZZANI; LORDELO, 2012, p. 19).

Dentre os procedimentos para a efetivação deste estudo, menciona-se a submissão do Projeto de Pesquisa ao Comitê Permanente de Ética em Pesquisa com Seres Humanos (Copep), UEM. O questionário foi desenvolvido no Google Docs. A coleta de dados se deu via e-mail, facebook e whatsapp, nos meses de novembro e dezembro de 2017 e janeiro, fevereiro e março de 2018. A amostra da pesquisa foi constituída por 126 (cento e vinte e seis) sujeitos que se dispuseram a responder ao questionário. Finalizada a coleta, seguiu-se a orientação de Bardin (2016), ao indicar a necessidade de se realizar a pré-análise, a exploração do material e a inferência.

A análise dos efeitos da política desenvolvida pelo Sistema UAB foi realizada com base no perfil dos egressos do curso de Pedagogia EaD/UEM, turma 2009, e em 3 (três) categorias de análise, indissociáveis ao se tratar da formação docente: 1-formação inicial de professores; 2- profissionalização docente; e 3-valorização profissional, conforme esclarece Bardin (2016). Para essa autora, a categorização se constitui em:

[...] uma operação de classificação de elementos constitutivos de um conjunto por diferenciação e, em seguida, por reagrupamento segundo o gênero (analogia), com critérios previamente definidos. "As categorias são rubricas ou classes, as quais reúnem um grupo de elementos (unidades de registro, no caso da "análise de conteúdo") sob um título genérico, agrupamento esse efetuado em razão das características comuns destes elementos". (BARDIN, 2016, p. 147).

Com relação ao perfil dos egressos do curso de Pedagogia EaD/UEM, turma 2009, constatou-se que $94 \%$ dos pesquisados são do gênero feminino e 6\% do gênero masculino. Nesta pesquisa, confirmou-se o que Gatti (2010) já havia 
identificado em suas pesquisas, a feminização da docência no Brasil, datada desde o final do século XIX, com a criação das Escolas Normais, em que mulheres eram maioria no trabalho do magistério. Com relação à faixa etária desses sujeitos, verificou-se que $42 \%$ possuíam entre 40 e 49 anos de idade, $35 \%$ de 30 a 39 anos, $13 \%$ com mais de 50 anos e $10 \%$ entre 20 e 29 anos.

\subsection{Formação inicial de professores}

Com a LDBEN- Lei n. 9.394/96 (BRASIL, 1996), em especial, o Artigo 87 que preconiza a Década da Educação, a qualificação mínima admitida para atuação na Educação Básica passa a ser a formação em nível superior. Maués (2003) identifica, nesse período, a expansão do número de cursos destinados à formação de professores correlacionados à meta estabelecida pelo Brasil, no tocante à universalização da Educação Básica.

Gatti, Barreto e André (2011) enfatizam a importância da formação de professores na sociedade contemporânea:

[...] a formação inicial de professores tem importância ímpar, uma vez que cria as bases sobre as quais esse profissional vem a ter condições de exercer a atividade educativa na escola com as crianças e os jovens que aí adentram, como também, as bases de sua profissionalidade e da constituição de sua profissionalização. (GATTI; BARRETO; ANDRÉ, 2011, p. 89).

Dourado (2008) identifica, a partir de 2002, um crescimento de políticas para a formação docente com ênfase na EaD. Portanto a compreensão dos retornos da política propalada pelo Sistema UAB para seus egressos torna-se relevante, visto que essa política objetiva principalmente a formação de professores atuarem na Educação Básica.

A análise da escolarização dos egressos do curso de Pedagogia EaD/UEM, turma 2009, anterior à realização da referida graduação, revela que, para 69\% dos pesquisados, esse curso foi sua primeira licenciatura, enquanto que, para $31 \%$, foi a segunda graduação.

Sobre as principais razões dos pesquisados terem cursado a Pedagogia EaD/ UEM, observou-se que, para 42\%, um número significativo de egressos, o curso permitia aquisição de conhecimentos na sua área de interesse e, para 19\%, por ser um curso com boas possibilidades profissionais. Constatou-se assim, que os dados encontrados na pesquisa se contrapõem ao que Maués (2003) relata sobre 
políticas de formação docente, ao assinalar que esses cursos visam, prioritariamente, à profissionalização. Verificou-se, ainda, que para $74 \%$ dos egressos o curso atendeu completamente suas expectativas de formação.

Observou-se que $48 \%$ dos egressos já trabalhavam na área da educação ao iniciarem essa graduação, e 52\% não trabalhavam. Desenvolviam suas atividades, principalmente no Ensino Fundamental I e na Educação Infantil. Sobre o vínculo empregatício dos que trabalhavam na Educação, 65\% eram concursados, 33\% indicaram outros vínculos e $2 \%$ eram estagiários.

\subsection{Profissionalização docente}

Guimarães (2004) identifica a ampliação da discussão sobre profissionalização docente em diversos países. Para esse autor, o conceito de profissionalização encontra-se diretamente ligado a uma série de etapas que o professor percorre, em que o ato de ensinar perde o caráter espontâneo e torna-se profissão.

O autor observa que a atividade docente deve-se contrapor à atividade provisória, necessitando assim, de formação, pois a formação inicial deve ser compreendida como "pedra de toque" para a profissionalização. Assim, a profissionalização ultrapassa a formação inicial, engloba melhores condições de trabalho e de remuneração.

Nesse sentido, a interpretação das respostas dos egressos do curso de Pedagogia EaD/UEM, turma 2009, acerca da ocupação posterior à conclusão desse curso, o vínculo empregatício posterior à conclusão do referido curso e a forma de ingresso no trabalho, revelaram que $48 \%$ dos egressos continuaram trabalhando na área da Educação, 41\% ingressaram na Educação e 11\% não estão trabalhando nessa área.

Em consonância com as Diretrizes Curriculares Nacionais para o Curso de Pedagogia (BRASIL, 2006a) que ampliaram o campo de atuação do pedagogo para além da docência, incluindo a gestão dos processos pedagógicos e produção de conhecimento em processos escolares e não escolares, atestou-se que os pesquisados exercem funções de docência na Educação Básica, no Ensino Técnico e tutoria em cursos na modalidade a distância. Desempenham atividades de gestão em redes municipais e estaduais de ensino.

Em relação ao vínculo empregatício, após a conclusão do curso de Pedagogia EaD/UEM, turma 2009, identificou-se que 69\% dos egressos são servidores 
municipais, 20\% servidores estaduais e 11\% trabalham em instituições privadas. Constatou-se que, para $91 \%$ dos pesquisados, a realização da licenciatura contribuiu para o seu ingresso na área da Educação. Desse modo, pode-se verificar que a realização do referido curso possibilitou a entrada e a permanência de um número significativo de sujeitos na área de Educação.

\subsection{Valorização profissional}

Dada a importância do professor nos processos formativos da sociedade atual, evidencia-se a necessidade da valorização profissional se constituir como um princípio da Educação para que se possa cobrar dos governantes ações que viabilizem na prática a devida valorização dos profissionais da Educação. Nessa direção, Volsi (2016) salienta que, na legislação educacional brasileira ${ }^{6}$, as políticas de formação são tratadas indissociáveis da valorização profissional. No entanto a valorização aparece mais enquanto discurso do que na prática.

Carvalho e Wonsik (2015) observam que a política de valorização profissional em nosso país poderia ser interpretada como avançada, visto que possuímos ampla legislação vigente. De acordo com as autoras, a necessidade de reconhecimento social do docente no Brasil, diferentemente de outros países, resultou no aumento das expectativas em relação ao desempenho desse profissional, bem como a culpabilização deste pelo desempenho insuficiente das escolas. Assim, o protagonismo do professor expresso na legislação educacional, constitui-se um instrumento de condução do professor ao sobretrabalho, caracterizado pelo aumento de suas atribuições.

Com base nas observações anteriores sobre a valorização profissional, verificaram-se junto aos egressos do curso de Pedagogia EaD/UEM, turma 2009, suas percepções em relação à situação profissional de cada sujeito após a conclusão do referido curso. Para $80 \%$ dos pesquisados, ocorreu uma maior valorização profissional mediante a conclusão da licenciatura. E isso se deu principalmente em razão de os egressos trabalharem em município ou estado que possui Plano de Cargos e Salários.

\footnotetext{
${ }^{6}$ LDBEN - Lei n. 9.394/96 (BRASIL, 1996); Lei do Fundo de Manutenção e Desenvolvimento da Educação Básica e de Valorização dos Profissionais da Educação- Fundeb (BRASIL, 2007); Lei do Piso Salarial Nacional para os Profissionais do Magistério Público da Educação Básica (BRASIL, 2008).
} 
Dentre as melhorias ocorridas na vida desses egressos merecem destaque: 1- passar em concurso público municipal e estadual; 2- trabalhar como professor regente na Educação Infantil e anos iniciais do Ensino Fundamental; 3-trabalhar como professor pedagogo e professor tutor; 4- continuar estudando (realizar pós-graduação, mestrado/doutorado); 5- trabalhar como professor palestrante em outro país; 6- Avanço na carreira e, consequentemente, obtenção de melhoria salarial. Mencionaram ainda melhorias na formação humana nas áreas pessoal, social e emocional.

Observa-se que, embora autores como Gatti, Barreto e André (2011) tenham identificado em seus estudos a discrepância salarial entre as várias regiões e municípios brasileiros, e que a carreira do magistério tem se apresentado pouco atrativa, para os egressos da Pedagogia EaD/UEM, turma 2009, essa licenciatura, no âmbito do Sistema UAB, possibilitou valorização profissional, incluindo aumento real de rendimentos.

Na perspectiva dos egressos, ocorreram-Ihe ainda melhorias na vida pessoal, tais como: aumento de autoestima, organização, foco e persistência, interação social, crescimento pessoal, valorização perante a sociedade, reconhecimento familiar, dentre outros.

\section{CONSIDERAÇÕES FINAIS}

Este artigo procurou apresentar os resultados de um estudo que objetivou analisar os efeitos da política desenvolvida pela UAB na perspectiva dos egressos do curso de Pedagogia, na modalidade a distância da Universidade Estadual de Maringá (UEM), turma 2009, no âmbito do Sistema UAB. A compreensão dos efeitos de tal política para seus egressos se deu com base em três categorias: formação inicial de professores, profissionalização docente e valorização profissional.

No que se refere à formação inicial, constatou-se que, para $69 \%$ dos egressos, essa foi sua primeira graduação. Esse curso proporcionou aquisição de conhecimento na área de interesse dos pesquisados, bem como gerou acesso ao ensino superior. Sobre a profissionalização docente, verificou-se que a realização da licenciatura em Pedagogia possibilitou que $48 \%$ dos egressos continuassem a trabalhar na Educação e $41 \%$ adentrassem nessa área. Portanto pode-se inferir que o curso contribuiu para a inclusão no mundo do trabalho. Com relação à valorização profissional, identificou-se que, para $80 \%$ dos pesquisados, o curso 
de Pedagogia EaD/UEM aferiu maior valorização, incluindo novas oportunidades de trabalho e maiores rendimentos.

Nesse sentido, salienta-se que o curso de Pedagogia EaD/UEM, turma 2009, desenvolvido pelo Sistema como uma política pública, possibilitou que professores em serviço ampliassem sua formação e que outros sujeitos pudessem realizar sua primeira graduação. Mediante os elementos trazidos por esta investigação, pode-se concluir que a referida política proporcionou efeitos positivos individuais e coletivos, visto que professores com formação em nível superior puderam contribuir para a melhoria da Educação Básica em seus municípios, estados e em nosso país.

\section{REFERÊNCIAS}

BALL, Stephen J. Intelectuais ou técnicos? O papel indispensável da teoria nos estudos educacionais. In: BALL, Stephen J.; MAINARDES, Jefferson (Org.). Políticas Educacionais: questões e dilemas. São Paulo: Cortez, 2011. p. 78-99.

BALL, Stephen J. Education reform: a critical and post structural approach. Buckingham: Open University Press, 1994.

BALL, Stephen J.; MAGUIRE, Meg; BRAUN, Annette. Como as escolas fazem as políticas: atuação em escolas secundárias. Tradução: Janete Bridon. Ponta Grossa: UEPG, 2016.

BARDIN, Laurence. Análise de conteúdo. Tradução: Luís Antero Reto. São Paulo: Edições 70, 2016.

BOWE, Richard; BALL, Stephen J; GOLD, Anne. Reforming education \& changing schools: case studies in Policy Sociology. London: Routledge, 1992.

BRASIL. Lei n. 11.738, de 16 de julho de 2008. Institui piso salarial profissional nacional para profissionais do magistério público da educação básica. Diário Oficial da União, Brasília, DF, 17 jul. 2008.

BRASIL. Ministério da Educação. Lei n. 11.494, de 20 de junho de 2007. Regulamenta o Fundo de Manutenção e Desenvolvimento da Educação Básica e de Valorização dos Profissionais da Educação - Fundeb. Brasília, DF: MEC, 2007. Disponível em: http://www. planalto.gov.br/ccivil_03/_Ato2007-2010/2007/Lei/L11494.htm. Acesso em: 10 abr. 2016.

BRASIL. Conselho Nacional de Educação, Conselho Pleno. Resolução CNE/CP n. 1, de 15 de maio de 2006. Institui Diretrizes Nacionais para o Curso de Graduação em Pedagogia, licenciatura. Diário Oficial da União, Brasília, DF, 16 maio 2006a. 
BRASIL. Decreto n. 5.800, de 8 de junho de 2006. Dispõe sobre o sistema Universidade Aberta do Brasil. Diário Oficial da União, Brasília, DF, 9 jun. 2006b.

BRASIL. Ministério da Educação. Edital n. 1, de 20 de dezembro de 2006. Segunda Chamada Pública para Seleção de Polos Municipais de Apoio Presencial e de Cursos Superiores de Instituições de Ensino Superior a Distância para o Sistema UAB. Diário Oficial da União, Brasília, DF, 20 set. 2006c.

BRASIL. Ministério da Educação. Decreto n. 5.622, de 19 de dezembro de 2005. Regulamenta o art. 80 da Lei no 9.394, de 20 de dezembro de 1996, que estabelece as diretrizes e bases da educação nacional. Diário Oficial da União, Brasília, DF, 20 dez. 2005a.

BRASIL. Ministério da Educação. Edital n. 1, de 20 de dezembro de 2005. Chamada Pública para Seleção de Polos Municipais de Apoio Presencial e de Cursos Superiores de Instituições Federais de Ensino Superior a Distância para o Sistema UAB. Diário Oficial da União, Brasília, DF, 20 dez. 2005b.

BRASIL. Ministério da Educação. Fórum das Estatais pela Educação. Projeto: Universidade Aberta do Brasil. Brasília, DF, 2005c. Disponível em: http://portal.mec.gov.br/arquivos/ pdf/universidade.pdf. Acesso em: 10 mar. 2017.

BRASIL. Decreto n. 2.494, de 10 de fevereiro de 1998. Regulamenta o art. 80 da Lei $n$. 9.394, de 20 de dezembro de 1996, e dá outras providências. Diário Oficial da União, Brasília, DF, 11 fev. 1998.

BRASIL. Lei n. 9.394, de 20 de dezembro de 1996. Estabelece as diretrizes e bases da educação nacional. Brasília, DF: 1996.

BRASIL. Ministério da Educação. Plano Decenal de Educação para Todos. Brasília, DF: MEC, 1993.

CARVALHO, Elma Júlia Gonçalves; WONSIK, Ester Cristiane. Políticas educacionais: valorização ou precarização do trabalho docente. Revista Contrapontos-Eletrônica, Itajaí, v. 15, n. 3, p. 373-93, set./dez. 2015.

COSTA, Maria Luisa Furlan. Política pública para o ensino superior a distância e a implementação do Sistema Universidade Aberta do Brasil no Estado do Paraná. 2010. 186f. Orientador: Maria Teresa Miceli Kerbauy. Tese (Doutorado em Política e Gestão Educacional) - Universidade Estadual Paulista Júlio de Mesquita Filho, Araraquara, SP, 2010. 
DAZZANI, Maria Virgínia Machado; LORDELO, José Albertino Carvalho. A importância de estudos com egressos na avaliação de programas. In: LORDELO, José Albertino Carvalho; DAZZANI, Maria Virgínia Machado (Org.). Estudos com estudantes egressos: concepções e possibilidades metodológicas na avaliação de programas. Salvador: EDUFBA, 2012. p. 15-22. Disponível em: https://repositorio.ufba.br/ri/bitstream/ri/6214/1/Estudo\%20 com\%20egressos.pdf. Acesso em: 4 abr. 2018.

DOURADO, Luiz Fernandes. Políticas e gestão da educação superior a distância: novos marcos regulatórios? Educação \& Sociedade, Campinas, v. 29, n. 104 [especial], p. 891917, out. 2008.

GATTI, Bernadete A; BARRETO, Elba Siqueira de Sá; ANDRÉ, Marli Eliza Dalmazo de Afonso. Políticas docentes no Brasil: um estado da arte. Brasília: UNESCO, 2011.

GATTI, Bernadete A. Formação de professores no Brasil: características e problemas. Educação \& Sociedade, Campinas, v. 31, n. 113, p. 1355-79, out./dez. 2010.

GOUVEIA, Cristiane Talita Gromann de. O Projeto Logos I/ em Rondônia: a implantação do projeto-piloto e as mudanças em sua organização político-pedagógica. 2016. $159 f$. Orientadora: Arlete de Jesus Brito. Dissertação (Mestrado em Educação) - Universidade Estadual Paulista "Júlio de Mesquita Filho", Instituto de Biociência, Rio Claro, SP, 2016. Disponível em: https://repositorio.unesp.br/bitstream/handle/11449/134221/gouveia_ ctg_me_rcla.pdf?sequence=3. Acesso em: 10 maio 2017.

GUIMARÃES, Valter S. Formação de professores: saberes, identidade e profissão. Campinas, SP: Papirus, 2004.

LACÉ, Andréia Mello. A Universidade Aberta do Brasil (UAB): das origens na ditadura militar ao século XXI. 2014. 313f. Orientador: Cláudio Lúcio Mendes. Tese (Doutorado em Educação) - Universidade de Brasília, Faculdade de Educação, Brasília, DF, 2014. Disponível em: http://www.repositorio.ufop.br/bitstream/123456789/9243/1/ DISSERTA\%C3\%87\%C3\%830_Forma\%C3\%A7\%C3\%A3oDocenteContexto.pdf em: 11 ago. 2016.

MAINARDES, Jefferson. Reflexões sobre o objeto de estudo da política educacional. Laplage em Revista (Sorocaba), v. 4, n. 1, p. 186-201, jan./abr. 2018. Disponível em: file:///C:/Users/sguie/Desktop/Mainardes\%202018.pdfAcesso em: 20 out. 2018.

MAINARDES, Jefferson. A abordagem do "ciclo de políticas" e suas contribuições para a análise da trajetória de políticas educacionais. Revista Atos de Pesquisa em Educação, v. 1, n. 2, p. 94-105, maio/ago. 2006. 
MAINARDES, Jefferson; MARCONDES, Maria Inês. Entrevista com Stephen J. Ball: um diálogo sobre justiça social, pesquisa e política educacional. Educação \& Sociedade, Campinas, v. 30, n. 106, p. 303-18, jan./abr. 2009. Disponível em: http://www.scielo.br/ pdf/es/v30n106/v30n106a15.pdf. Acesso em: 15 de mar. 2016.

MAUÉS, Olgaíses Cabral. Reformas internacionais da educação e a formação de professores. Cadernos de Pesquisa, n. 118, São Paulo, mar. 2003. Disponível em: http:// www.scielo.br/scielo.php?script=sci_arttext\&pid=S0100-15742003000100005. Acesso em: 15 abr. 2018.

PETERS, Otto. A educação a distância em transição: tendências e desafios. São Leopoldo, RS: Ed. Unisinos, 2003.

UnIVERSIDAde eStAdUAL De MARINGÁ. Projeto Pedagógico do Curso de Pedagogia Licenciatura Plena: modalidade de educação a distância. Maringá, 2008.

VOLSI, Maria Eunice França. Políticas de valorização de professores da educação básica pós-Constituição Federal de 1988. 2016. 209f. Orientador: Mário Luiz Neves de Azevedo. Tese (Doutorado em Educação) - Universidade Estadual de Maringá, Maringá, PR, 2016.

\section{Sobre as autoras:}

Silvana Aparecida Guietti - Doutora em Educação pela Universidade Estadual de Maringá. Professora Pedagoga da SEED/PR. Professora da Educação Básica do município de Cianorte, PR. Membro do Grupo de Pesquisa Educação a Distância e Tecnologias Educacionais (GPEaDTEC). E-mail: sguietti@bol.com.br, Orcid: http:// orcid.org/0000-0001-8338-6292

Maria Luisa Furlan Costa - Doutora em Educação Escolar pela Universidade Estadual Paulista "Júlio de Mesquita Filho" (UNESP/Araraquara). Professora Associada do Departamento de Fundamentos da Educação e do Programa de Pós-Graduação em Educação da Universidade Estadual de Maringá (UEM). Líder do Grupo de Pesquisa Educação a Distância e Tecnologias Educacionais (GPEaDTEC). E-mail: luisafurlancosta@gmail.com, Orcid: http://orcid.org/0000-0002-7838-0459

\section{Recebido em março de 2019 Aprovado em agosto de 2019}


